\title{
Modernization of the Tax Science: Methodology and New Paradigms
}

\author{
Djaxongir R. Zaynalov" and Zarif O. Ahrorov^* \\ \#Professor, Samarkand institute economics and services, Samarkand, Uzbekistan \\ ^Independent researcher, Samarkand institute economics and services, Samarkand, Uzbekistan \\ Received 12 March 2019, Accepted 14 May 2019, Available online 16 May 2019, Vol.7 (May/June 2019 issue)
}

\begin{abstract}
The article is devoted to the study of the development of the science of taxation, and the worldview of various authors on this aspect of the financial category is considered and cited. Also, a comparative characteristic of the tax burden of different countries, an analysis of the reduction of the tax burden in Uzbekistan for different categories of enterprises was carried out. The outcome was the conclusions about changing the very style of natural scientific thinking about tax in Uzbekistan, and also that the principle of self-organization or self-regulation should be the basis of the paradigm of thinking about tax.
\end{abstract}

Keywords: Tax, taxation, nature of tax, taxation principle, tax ratio

\section{Introduction}

The discussion on the nature of the tax that has developed in the pages of the journal, the monograph, seems to be very timely, despite its seeming isolation from current economic problems. In fact, the development of real approaches to their solution depends largely on the overall assessment of the current economic situation, the choice of the specific model of transition to a market economy that will help improve the country's finances and strengthen the tax relations of budget entities. Important here is the analysis of trends in the development of tax relations and economic thought about the nature of the tax.

The scale and radical changes that have recently taken place in all spheres of social and economic life, the ongoing modernization of the economic life of society and the changing style of scientific thinking itself about tax all dictate the need to search for a new conceptual apparatus, principles and methods of research, the essence of the tax including and the science of tax.

The search for a new paradigm of tax science is directly related to the identification of new principles for generalizing accumulating empirical material, improving its analysis methods and developing deeper and broader concepts. Among the latter is the concept of tax, which arose in the framework of a new interdisciplinary area of research, called synergetics. With its help, it is possible to characterize with a greater degree of adequacy the most complicated processes about tax relations, starting from

*Corresponding author's ORCID ID: 0000-0003-4403-9137 DOI: https://doi.org/10.14741/ijmcr/v.7.3.11 the behavior of the tax mechanism and ending with the functioning of such social institutions as tax management, the science of tax, tax culture and especially taxation. We hope that the contours of the new paradigm about which Acad. L. Abalkin will become clearer and more distinct if we replace the intuitive formulations with more specific and precise terms of the new concept of self-organization (Abalkin, 2011). Here it is necessary, first of all, to look from this point of view at market relations and mechanisms.

Despite the differences and often the opposite of interests, goals and aspirations of the participants in tax relations, in the end, a balance is established between taxpayers and tax recipients. Such an equilibrium is, firstly, relative, temporary, as tax payments continue to fluctuate around a certain optimal value. Secondly, the optimal value of taxes does not arise spontaneously, but through a conscious decision, by the desires and interests of taxpayers and its recipients. The mechanism promoting the appearance of such an equilibrium of a solution, or, more precisely, of an optimal dynamic order, is competition. Where there are no obstacles to competition or not they are insignificant, there tax relations are the most prominent.

\section{Literature Review}

These ideas of self-organization of the market mechanism in a clear and figurative form expressed more than two centuries ago A. Smith in his fundamental work "An Inquiry into the Nature and Causes of the Wealth of Nations». "...every individual necessarily labours,- says he,- to render the annual revenue of the society as great 
as he can. He generally, indeed, neither intends to promote the public interest, nor knows how much he is promoting it. By preferring the support of domestic to that of foreign industry, he intends only his own security; and by directing that industry in such a manner as its produce may be of the greatest value, he intends only his own gain, and he is in this, as in many other cases, led by an invisible hand to promote an end which was no part of his intention. Nor is it always the worse for the society that it was no part of it. By pursuing his own interest he frequently promotes that of the society more effectually than when he really intends to promote it. I have never known much good done by those who affected to trade for the public good» (Smith, 2007).

The idea of "the nature of tax", "principles of taxation", "tax mechanism", "tax relations", formed the basis of classical political economy. It was assumed that the tax is able to adjust and regulate the economy. Such notions dominate not only in the writings of $A$. Smith (2007), D. Ricardo (2001), D.S. Mill (2015) and other classics, but also gain further strength in countries with developing market economies. However, even now the influential monetarist school holds a similar view and stands for support to regulate the economy with market mechanisms, in particular, with tax mechanisms.

\section{Findings and Results}

How do modern scientists explain the process of regulating the economy and the emergence of a conscious order on it, manifested in the establishment of a balance between taxpayers and tax recipients?

One of the first approaches is based on our view of the cybernetic principle of negative feedback. The possibilities of such a connection are formulated by biologists who have noticed the similarities between the functioning of the market and a living organism. Just as living systems maintain a state of stable dynamic equilibrium, or, in the terminology of William Cannon, homeostasis, so the market can carry out self-regulation through negative feedback. If the demand for goods exceeds supply, then the price for them increases. When the supply is more than demand, the price for them falls. On this basis, even opinions were expressed that A. Smith long before the creator of cybernetics $N$. Wiener used the principle of feedback in his "Wealth of Nations". "The invisible hand," which very precisely regulates prices, wrote an eminent American biologist and ecologist G. Hardin, is undoubtedly a mechanism of homeostasis .... In the free market, prices are ultimately regulated by negative feedback" (Hardin, 1959).

However, the whole difficulty is to explain this connection or order in the tax system. Why, pursuing their own interests, do people often serve the public interest through tax relations in a more efficient way? How is the coordination of various goals and interests of people in the market through tax relations? To answer these questions, we must turn to a new concept of self- organization put forward by synergists. In contrast to cybernetics, synergetic seeks to identify the ways in which self-organization emerges, not so much in technical management systems, as in natural and socio-economic processes.

The merit of this science lies primarily in the fact that for the first time it theoretically substantiated and experimentally proved that, under strictly defined conditions, self-organization can occur in the simplest physical and physicochemical systems. The author of the very term "synergetic" G. Haken analyzed these processes in the work of a solid-state laser, and the Belgian scientist, Russian by origin, I. Prigogine investigated them in chemical reactions. In many ways, he relied in his conclusions on the experiments of Russian scientists $V$. Belousov and A. Zhabotinsky.

Obviously, the more complex the system is by its nature, the more specific and difficultly predictable the nature of self-organizing processes in it. If for simple hydrodynamic, meteorological, physical, physicochemical systems, an indispensable condition for the emergence of a new order and structure is, firstly, the open nature of the system, that is, the exchange of matter and energy with the medium, secondly, its disequilibrium and, thirdly, a sufficient distance from the thermodynamic equilibrium point (Haken 1980; Prigojin, 1986), a whole number of additional conditions are added to the tax system, many of which remain to be investigated, in particular, the nature of the tax, optimization of tax taxation mechanism and the relationship between the elements. At the very least, the role of each is greatly enhanced and one cannot abstract them, as in phenomena of inorganic nature.

It is important, however, to emphasize that the approach to tax and its nature from the standpoint of synergetics makes it possible to explain not only the existence but also the genesis, the emergence of order also in the processes of optimal taxation. But here it is necessary to apply for the description of specific processes to special concepts, methods and concepts of the science of taxation.

Let us try to show this on the example of selforganization of the tax mechanism. The emergence of the self-organization of the tax mechanism in open systems to which the tax relationship belongs, comes at a time when there is a certain coherence (consistency) between the actions of their constituent elements, in this case the participants of the tax system. According to supporters of the theory of marginal utility of U.S.Jevons, K.Menger, L.Valras, when exchanging goods, everyone is guided primarily by their subjective value, which is determined by the marginal utility of these benefits.

Although at the same time he relies on his individual scale of values and expresses his preferences on their importance, nevertheless, in the process of exchange, these scales are coordinated as a result of mutual influence, and on this basis, no one beforehand provides for the structure and order, which in traditional economic literature considered as an equilibrium, "cleansing" or 
even, according to A.Smit, the natural price, and in our opinion, the real value of the tax, since the tax as the price is associated with the subjective assessment of goods in their usefulness. Only the price and usefulness of the goods can provide not only the real amount of tax receipts, but its nature, since the true nature of the tax lies in the price of the useful goods. However, a representative of the marginal utility theory, E. BemBawerk, defines the market price as the resultant of the subjective assessments of the goods colliding in the market and the thing in which its price is expressed (Böhm-Bawerk, 1890).

F. Hayek in his last book, translated into Russian, characterizes research on the subjective revolution as a "coup, later called the" subjective revolution ", or the revolution of" marginal utility "in economic theory" (Hayek, 1991) Although later this theory supplemented the classical concept and became a neoclassical model of economics. Part of the price and utility, of course, are taxes.

There is no doubt that the concept of the subjective value of a commodity, which characterizes the usefulness for a certain subject, is a necessary addition to its objective value, revealed in the exchange process. Therefore, the price and utility can not ignore taxes. Based on the concepts and concepts of marginal utility theory, it is possible to reveal the content of the tax, to understand how tax relations arise and are formed through coordination and mutual correction of value scales. It is important to pay attention to the fact that such coordination occurs behind the backs of sellers and buyers unconsciously, although each of them acts quite consciously in achieving his goal. It is clear that the emergence of tax is the most difficult to explain in terms of strict determinism and mechanical causality, as classical political economy tried to do, and in particular, DS Mill, the author of the system of deductive and inductive logic. It is hardly possible to characterize these laws as tendencies that are realized with "iron necessity", on which Karl Marx insisted. In this regard, it is interesting to note that Hayek, referring to Reig, believes that "Marx himself after studying the works of Jevons and Menger, apparently, completely stopped further work on the problem of capital" (Hayek, 1991). It was the study of capital that made it possible to understand the essence and nature of economic phenomena, in particular, tax, and in this the great merit of Karl Marx (Hayek, 1991).

The market as an open system is also characterized by the continuous exchange of information through the mechanism of prices and tax. While the inorganic mechanisms of the system and most of the organic mechanisms of the systems interact with the market environment, they exchange mechanisms and elements of the tax system cannot function without the exchange of information. Of course, society in the form of production and labor also carries out continuous communication by means of taxes with the environment, but the specific feature of such relations as a whole is primarily taxable. Tax relations through the pricing mechanism inform the participants of tax relations about the opportunities that they have for the effective use of limited resources at their disposal. That is why, for example, Hayek considers competition as a discovery procedure (Hayek, 1991).

Thus, using the example of the market, we could see how using the basic concepts and principles of selforganization one can explain the regulating role of the "invisible hand" and thereby understand how spontaneous order arises, which manifests itself in achieving a balance between supply and demand. But such explanations do not reveal the main thing: the reasons for such stability and efficiency of the market and other public institutions that are formed in the process of a long and gradual development of the society itself. That is why we have to turn to clarify the connection between self-organization and the evolution of systems.

Open systems can be self-organizing. Self-organization is the ability to overcome internal limitations: the ability to achieve new, more stable states. Thus, selforganization of taxation is a more complex phenomenon than tax stabilization, since it is associated not only with adapting to changes in the external environment, but with the ability to overcome internal limitations. There is an evolution in more viable tax systems. The organization of the tax system itself is characteristic of all development processes. For a developing tax system, on the one hand, there are optimal and stable taxes, and on the other, a loss of optimality and stability, the destruction of one system and the creation of another optimal stable tax system.

\section{Optimization of taxation as the basis for the evolution of socio-economic development}

In the most general form, tax optimization means the consistency of interests of taxpayers and tax recipients. The need is always ahead of the volume of tax revenues in budgets of different levels. But despite this, taxes should be minimal. Otherwise, a high tax burden may restrain entrepreneurial activity and slow down investment policy, as a result of which the renewal of production assets has ceased. To be fair, it should be noted that $A$. Laffer made a significant contribution to managing the quantitative relationship between tax productivity and budget revenues, and the tax curve that he built was later called the Laffer curve (see Figure 1), which was the impetus for setting the tax limit rates in order to increase budget revenues, so optimization is usually achieved either by limiting the need for non-tax resources, or by increasing and optimizing non-tax revenues. 


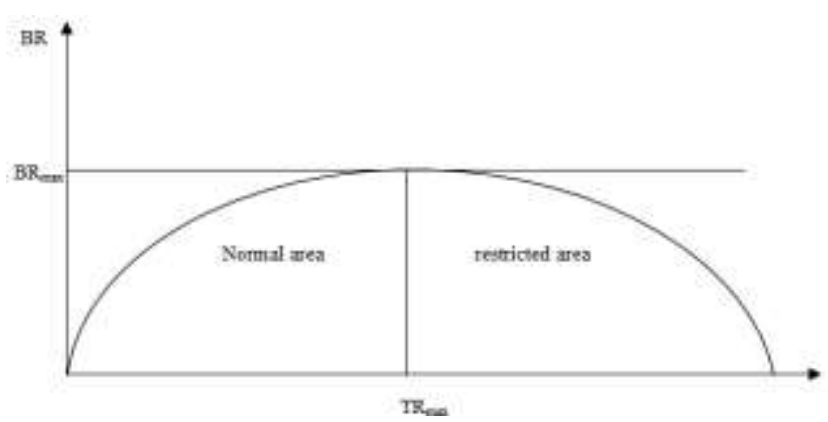

BR-Budget revenues; $B_{\mathrm{RMax}}-$ Maximum budget revenues; $\mathrm{TR}_{\mathrm{Max}}-$ Maximum tax rate

Fig. 1 Laffer Curve

Achievement optimization contributes to the tax mechanism. As a result of fluctuations in the tax rate, the amount of tax revenues and the need for resources from tax revenues level off: a tax rate and taxable base should be established at the point of their intersection. However, tax optimization is implemented slowly and gradually, through trial and error. In this sense, tax optimization can and should be considered as the basis of the evolutionary process, as a result of which the quality, characteristics, properties, skills, skills and other factors are selected that contribute to a better adaptation of the system to changing economic conditions. That which is useful for the survival and development of a tax optimization system is preserved and consolidated, and everything that impedes this is discarded and eliminated. But here there are significant differences between the systems of the nature of the tax and the system of taxation, which we will in the future be called optimal for short. In living nature, the useful reflexes acquired in the course of adaptation are not transmitted genetically to future generations, while the evolution of the tax system is characterized precisely by the assimilation and use of skills and behavioral norms that make groups, groups and communities of people better adapted to new tax systems and conditions its optimization.

In the market-oriented economic literature, the role of the pre-planned and top-down management of the tax system was excessively exaggerated. The processes of formation of the tax system are qualified as spontaneous and therefore bring disorganization into society, is considered inappropriate. Meanwhile, it was precisely from the diversity of goals, motives and aspirations of taxpayers that in the course of the evolution of the tax system, order gradually emerged and the socio-economic patterns based on it, based on which taxes operated more efficiently.

How to explain such a seemingly paradox? Why the diversity of interests, goals and motivations contributes to the achievement of a more sustainable order and an effective tax system than the desire to level them, to achieve unidirectionality and community? The answer to this question should be sought in the aspect of the gradual, evolutionary formation of the tax system during the centuries-old process of trial and error, where every step to success was supported by practical expediency, the achievement of the best conditions for the functioning of the tax system. This historical evolutionary selection of the best properties of the tax system contributed to the introduction and consolidation of such standards of conduct and order that best fit the changing conditions of society.

From a synergistic point of view, such processes can be legitimately regarded as self-organizing, in which coherence, i.e. the coordination of goals and motivations does not occur consciously and individually, but at the level they establish when the market mechanism of taxation functions or when complying with legislation, as well as other similar actions, is very strong because it is formed by selecting and correcting the most viable experience. In this regard, the historical evolution of the tax system is similar to the evolution of the organic, leading to an increase in the number of individuals, the most adapted to the changed conditions of their functioning (existence). However, since the organizational evolution of the tax system is associated with genetic factors, it occurs much more slowly than the evolution of the very nature of the tax.

The evolutionary nature of the tax and tax system as a whole is recognized by many prominent Western scholars. However, the evolutionary process of tax formation and the tax system is due to the paralle formation of national traditions, in particular, language, morality, culture, philosophy, etc. Referring to this nature of the interrelation of economic phenomena, $M$. Friedman emphasized from the very beginning the gradual nature of market formation and compared it the formation of morality, language and culture. The principle of "invisible hand" and economic freedom, in his opinion, shows how "a complex, organized, gradually developing system can evolve and thrive without any central control and how agreement in it can be achieved without any friction" (Friedman, 1980).

In contrast to Friedman, Hayek directly links sociohistorical evolution with self-organization and the establishment of extended spontaneous order. Proceeding from this, he tries to refute the idea of mutual aid and cooperation, considering that solidarity and altruism are inherent only to people living in small groups and in the wilderness stage. Moreover, he believes that "adherence to eternal moral precepts, such as" love your neighbor as yourself, "should prevent the spread of the expanded order" (Hayek, 1991). The inconsistency of such an assertion lies, firstly, in the fact that in it, without due justification, the principles of biological evolution are transferred to social evolution; secondly, even in the organic world, the current tax system is often complemented by cooperation; thirdly, the sociohistorical evolution undoubtedly implies the addition of the tax system with cooperation and mutual assistance. Of course, this task is not solved by the market, but by the state with the help of a properly implemented tax policy aimed primarily at social protection of the population. As 
for the established norms and traditions of morality, which, according to Hayek, interfere with the functioning of a better tax system, they do not interfere, but, on the contrary, contribute to social progress, especially at the modern stage of development of market relations. It is not by chance that many prominent representatives of evolutionary development oppose this, "in fact, success in life's struggles," declares M. Reuse, "is often achieved through cooperation and morality than through aggression" (Ruse, 1988).

Evolutionary processes do not exclude, of course, qualitative changes in socio-economic development, which will be discussed later. In the same way, selforganization, the result of which is not realized by the subjects participating in it, does not detract from the meaning of the conscious organization of management of the tax system. But here we meet with two extreme points of view, which are not difficult to find in the existing economic literature on the nature of taxes.

The conviction of the sufficiency of disclosure of the essence of the tax, starting from A.Smith, acquired the strength of prejudice. Such a view was inherent in not only the classical principles of taxation, but also its further modifications. The situation radically changed after the country's transition to a market economy, when the volume indicators of the economy fell by almost half. And this inevitably led to a recession in the economy, an unprecedented level of unemployment, a sharp decline in the living standards of the population.

But the developed classical theory about the nature of the tax and the tax system was not able to not only implement radical measures to get out of the current situation, but even to explain its reasons. Referring to the actions of certain economic phenomena adequate to taxes, J.M. Keynes rightly stated that the postulates of economic theory do not reflect the characteristics of the economic theory facts of experience"(Keynes, 1936). Keynes and his followers put forward the idea of macroeconomic regulation of the market through appropriate fiscal and monetary policies. And this meant that the mechanisms of the market and free enterprise are not fully self-regulating. Although in recent years, due to financial imbalances, Keynes's concept has been criticized by monetarists for underestimating the role of money, tax, price, etc. in macroeconomics, nevertheless, from a methodological point of view, it seems more convincing. In it from the point of view of synergetics, the formation of the theory of tax is complemented by its organization, regulation by the state and its governing bodies.

On the other hand, modern concepts of monetarists, supporters of the theory of rational expectations (TRE) and some others require a decisive turn from state regulation to completely autonomous. In other words, here taxes can be recognized as the only regulatory mechanism. The head of the monetarist school, $M$. Friedman, even demands the adoption of a corresponding bill on economic freedom (Friedman, 1980). We will not discuss the advantages and disadvantages of Keynesian, monetarist and other concepts of market regulation of the tax system based on the theory of tax. We are primarily interested in their general approach, their initial principles and final conclusions. Such an analysis is necessary: after all, the science of tax cannot fail to take into account the general tendencies of philosophical, sociological, and scientific thought in general. To be fair, it should be noted that the former science of the essence of tax was part of a general theory of the development of the tax system, which later became a unified system in the classical sense. Despite the emergence of many new approaches to the nature of taxes and research directions, the science of tax aims to continue the disclosure of "the most general, fundamental principles of the organization of the economic life of society in their close interaction with socio-political processes" (Abalkin, 2011). The concept of organization as a generic is more general in relation to the nature of the tax, just like the concepts: tax optimization, regulation of the tax system. From the modern point of view, they all rely on the original and therefore the most fundamental concept of tax, which implies modernization or orderliness as an indispensable condition. Modernization or orderliness, in our opinion, arise from chaos, disorder in the presence of certain conditions.

It is obvious that taxes, like any social system economic, cultural, humanitarian, etc. - since conscious, thinking beings operate in it, cannot develop without conscious organization. At the same time, the efficiency of the tax system, its activity is largely determined by the purposefulness, motivation, interests of the participants acting in it, due to the interaction that is unaware at the individual level, their interrelationships arise. Thus, the adequate functioning of the tax and other socio-economic mechanisms as a whole requires an addition to the current system of tax relations as an internal regulator by an external regulator, which is the state, and the actions of its governing bodies should be controlled by society. Concerning these problems, V. Leontyev writes: "For things to go well, you need wind, this is interest. Steeringstate regulation. The American economy has a weak steering wheel. You can't do what Reagan said: raise the sails, let the wind fill them, and go to the cabin to drink cocktails. I think the Japanese are doing it more correctly. Of course, they have a private initiative, but the state also plays a big role, influencing the development of the economy in a better direction "(Leontyev, 1990).

Consequently, what kind of "wind" to fill the "tax sails" so that the reform in our country can make successful progress? The first and obvious condition is, of course, the economic interest of people in the results of their work. It will contribute to the unification of the tax system, and thereby increase the productivity of social labor. Forms of such unification can be very different, prompted by life itself. Different forms of individualized ownership (group, cooperative, joint-stock and other nonstate) should correspond to these forms. This also 
includes private property. Relying on individualized property, which has a genuine owner, will not only help preserve and enhance this property, but will also be a powerful incentive for the transformation of the entire tax system. That is why tax reform, as it seems to us, should begin first of all in separate economic units of microeconomics.

The efforts of economists should be aimed at creating a decentralized system of tax relations in which a large number of independent producers and consumers in each industry could compete with each other with the help and influence of unified elements of the tax system.

An example is the Concept of Improving the Tax Policy of the Republic of Uzbekistan (Decree of the President of the Republic of Uzbekistan "On the Concept of Improving the Tax Policy of the Republic of Uzbekistan" from UP5468 06/29/2018), where the mechanism for building a tax system in accordance with the principles reflecting the objective requirements of linking taxation system with qualitative and quantitative parameters of the Program of the strategy of socio-economic development of the country for 2019-2021, which will allow in the future, reduce or neutralize the negative effects of the existing tax system. The established taxation system also relies on internal conditions, features of development and economic interests of each sector of the economy, including individuals, that is, takes into account specific features, and an example is the reduction of the tax burden starting from 2019 (see: Table 1 and 2 ).

Table 1 Tax burden change following the example of trade enterprises ( $\mathrm{mln}$. Sums)

\begin{tabular}{|c|c|c|c|}
\hline Types of taxes & Currently & $\begin{array}{c}\text { According to } \\
\text { Concept }\end{array}$ & Difference \\
\hline Turnover & 5000,0 & 5000,0 & - \\
\hline Number of & 15 & 15 & - \\
\hline The wage fund & 167,0 & 167,0 & $-5,1$ \\
\hline $\begin{array}{c}\text { Single social } \\
\text { payment }\end{array}$ & 25,1 & 20,0 & $-202,0$ \\
\hline \begin{tabular}{c} 
Single tax payment \\
\hline Profit tax
\end{tabular} & 202,0 & 0 & 116,9 \\
\hline Subsurface Tax & - & 116,9 & 2,1 \\
\hline Property tax & - & 2,1 & 10,0 \\
\hline Land tax & - & 10,0 & 1,2 \\
\hline The total tax \\
amount
\end{tabular}

Source: Data Tax State Committee of the Republic of Uzbekistan
The impact of the standards stipulated by the Concept of Improving the Tax Policy of the Republic of Uzbekistan on the tax burden of small businesses can be traced in the table (see Table 2).

Table 2 The impact of standards stipulated by the Concept on the tax burden of small businesses

\begin{tabular}{|c|c|c|}
\hline Types of taxes & Currently & $\begin{array}{c}\text { According to } \\
\text { Concept }\end{array}$ \\
\hline Single social payment & $15 \%$ & $12 \%$ \\
\hline Insurance fee & $8 \%$ & $0 \%$ \\
\hline Income tax & $7,5 \%-22,5 \%$ & $12 \%$ \\
\hline Corporate tax & $0 \%$ & $12 \%$ \\
\hline Single tax payment & $10 \%$ & $4 \%$ \\
\hline Property tax & $0 \%$ & $2 \%$ \\
\hline Land tax & $0 \%$ & By area \\
\hline
\end{tabular}

Source: Data Tax State Committee of the Republic of Uzbekistan

The measures taken to reform the tax contribute to reducing the tax burden (see: Table 3 ). The measures taken also contribute to reducing the tax burden compared to other countries of the world (see: Table 3).

Table 3 Change the tax burden of legal entities

\begin{tabular}{|c|c|c|c|}
\hline Types of taxes & Currently & $\begin{array}{l}\text { According } \\
\text { to Concept }\end{array}$ & Difference \\
\hline $\begin{array}{c}\text { Taxable income of } \\
\text { taxpayers }\end{array}$ & $\begin{array}{c}9459,4 x \\
14 \%\end{array}$ & $\begin{array}{c}9459,4 \times \\
12 \%\end{array}$ & \\
\hline Income tax & 1324,3 & 1135,1 & $-189,2$ \\
\hline $\begin{array}{c}\text { Profit of commercial } \\
\text { banks }\end{array}$ & $\begin{array}{c}2531,8 x \\
22 \%\end{array}$ & $\begin{array}{c}2531,8 x \\
20 \%\end{array}$ & \\
\hline Income tax & 557,0 & 506,4 & $-50,6$ \\
\hline $\begin{array}{c}\text { Taxable part of the } \\
\text { property of legal } \\
\text { entities }\end{array}$ & $\begin{array}{c}28800,0 x \\
5 \%\end{array}$ & $\begin{array}{l}28800,0 x \\
2 \%\end{array}$ & \\
\hline Property tax & 1440,0 & 576,0 & $-864,0$ \\
\hline $\begin{array}{l}\text { Commodity turnover } \\
\text { of large enterprises }\end{array}$ & $\begin{array}{c}162718,8 \times \\
3,2 \%\end{array}$ & $\begin{array}{c}162718,8 x \\
0 \%\end{array}$ & \\
\hline $\begin{array}{l}\text { Extrabudgetary } \\
\text { funds tax }\end{array}$ & 5207,0 & 0 & $-5207,0$ \\
\hline
\end{tabular}

Source: Data Tax State Committee of the Republic of Uzbekistan

Only through the modernization of the science of tax does a relatively painless transition to a unified tax system become possible. A purely monetarist policy and an increase in the tax pressure on the producer under such conditions can only lead to disruption of the economy or to unpredictable consequences. The transition to a unified tax system requires deeply thought out and carefully weighed control over this move; in countries with a highly developed market economy, government intervention is limited to regulating the existing and working tax mechanism, but we have to create it. In addition, given the long-standing traditions of the people, their desire for community life, mutual assistance and mutual assistance, it is necessary to promote the development of such activities that would contribute to the unification of the tax system, most fully and harmoniously combine individual and common motivations, aspirations and goals of certain groups, collectives and society as a whole. 
In this regard, the question of the nature of the tax is of particular importance. In synergy, this means the collective behavior of the elements of the tax system as a result of their coherent, coordinated interaction. Strictly speaking, it is impossible to speak about the unification of a system without the collective behavior of its elements. But like any system and tax system is affected by external factors. Such an impact can speed up or slow down the development of this system or even destroy it. Applying this general principle of synergetics to the tax system, we can conclude that taxes will function effectively and develop successfully only when, on the one hand, taxpayers are disciplined, on the other, when the impact of an external organizing factor, in particular, the state and its institutions, will contribute to achieving the goals of tax relations. Not only an established system of tax relations, but also the process of its formation requires complementarity. In this regard, it appears that the search for a new paradigm of the science of tax must necessarily be conducted, first of all, taking into account the modernization of the organizational structures of the country's socio-economic systems.

The term "paradigm", widely used in the methodology of science with the "light hand" of T. Kuhn (Kuhn, 2012), is often used in a variety of ways, which creates unnecessary confusion. In order to avoid it, we will further understand by the paradigm the fundamental theory that dominates in a particular science at a certain moment of its development. Such a paradigm for classical mechanics is theory formulated by Newton and refined by his followers for classical political economy - the theory of Smith and Ricardo. Of course, with the development of science, in particular, about tax, deeper and more general theories emerge, which become new paradigms, although the old paradigms are not rejected at all, but the boundaries of their application are more clearly outlined. The opinion is also widespread that the new paradigm, like the more fundamental theory in general, contains the old one as a particular or extreme case. Therefore, we can say, for example, that "the neoclassical theory, which incorporated marginal analysis, as a special case assumes the classical paradigm.

At the heart of any paradigm is some general idea or concept that finds its specific expression, firstly, in the original or original concepts, secondly, in the system of basic principles, laws, or fairly plausible hypotheses. It is these elements that make up the conceptual core of the paradigm, and the efforts of theorists and economists should be directed to their search, formulation and justification. At present, there are different approaches in the economic literature to analyzing the prospects for the development of the tax system, but none of them provides a unified, holistic understanding of the future by developing the tax system in accordance with the requirements of the economy. Most likely, the answer to this question can be found by identifying the rational aspects that exist in each approach and integrating them into a single, integrated tax system. But for such a union, or more precisely, a synthesis, it is necessary to find the basic, guiding tax definition, by which all approaches can be connected within a single paradigm.

To approach the solution of this problem, we must first answer the cardinal question: is the tax a function of the economy, the economy, or is the economy itself a function of the tax? This series of general and preliminary questions largely predetermines the content of the science of tax. Economic determinism, grown on the basis of classical political economy and the mechanistic scientific worldview of the seventeenth and eighteenth centuries, essentially reduces taxes to the level of a thing, an object in the economic mechanism, devoid of its inherent activity. From this directly follows the postulate of the immutability and eternity of the tax. This style of thinking, which was formed under the influence of the successes achieved on the tax, should, according to the plan of its creators, impart to the tax system the same accuracy, clarity and consistency, and thereby ensure progress. However, such attempts increasingly came into conflict with the real facts of economic and social life. On this basis, the anti-positivist direction of the science of tax emerged, which appeared in the form of a phenomenological concept. All of them denied mechanization and rigid determinism in understanding the essence of the tax, emphasized the great importance of the uniqueness of the tax in social processes.

\section{Conclusion}

Progress in the tax system has led to the rejection of a mechanistic worldview and to a change in the very style of natural scientific thinking about tax. If before the world was considered as a mechanism, now it is compared with the body. Accordingly, the statistical approach is replaced by a dynamic, evolutionary one, in which taxation processes play a decisive role. That is why it seems that the principle of self-organization or self-regulation should become the basis of the paradigm of thinking about tax which, as was shown above, makes it possible to adequately describe the functioning of the tax relationship system and the role of tax self-regulation in achieving a stable order, that is, market optimization.

In addition, such an approach makes it possible to understand that, due to a multitude of random factors, the development of such complex dynamic tax systems as economic, social and humanitarian systems cannot be predicted accurately and reliably. The processes occurring in the tax system, as a rule, are non-linear, and therefore the effect of random factors can change the trajectory of the tax system. It means that all our economic forecasts can claim only for one or another degree of reliability, and the models and development scenarios that we construct have only socio-economic value, which contributes to raising the theory of tax and the tax system to a higher quality level. This is important because thanks to this level it will be possible to ensure the smooth construction of taxes in the revenues of budgets of all levels. 


\section{References}

[1]. From economic theory to the concept of a long-term strategy // L. Abalkin. Problems of modern Russia. M., 2011, p. 39-47.

[2]. Smith, Adam. An Inquiry into the Nature and Causes of the. Wealth of Nations. Edited by S. M. Soares. MetaLibri Digital. Library, 29th May 2007. pp. 349

[3]. David Ricardo, On the Principles of Political Economy and Taxation, Kitchener: Batoche Books, 2001.

[4]. John Stuart Mill. Principles of Political Economy (Kindle Edition), Some Good Press Kindle Edition, 2015. 659 p.

[5]. Hardin G. Nature and Man's Fate. New York,1959, p.52

[6]. Haken G.Sinergetika. Translation from English M.1980

[7]. Prigojin I.R., Stengers I. Order from Chaos. M., 1986
[8]. Böhm-Bawerk, Eugen von; Smart, William (1890). Capital and Interest, a critical history of economical theory. London, New York: Macmillan and Co. Retrieved 17 August 2018.

[9]. Hayek, F.A. The Fatal Conceit: The Errors of Socialism. The University of Chicago Press. 1991. p. 169.

[10]. Friedman M.R. Free to Choose: A Personal Statement. New York, Harcourt Brace, 1980,p.6,7

[11]. Ruse M., 1988.Evolutionary Ethics: Healthy prospect or Last Infirmity? In: Matthen and Linsky, 1988.

[12]. Keynes, The General Theory of Employment, Interest and Money. Macmillan Cambridge University Press, for Royal Economic Society in 1936

[13]. Leontyev V.V. Economic Essay. Theories, Studies, Facts and Policy. 405 p. M.: Polizdat, 1990

[14]. Thomas Kuhn. Paradigm Shift Award. American Chemical Society. Retrieved September 19, 2012. 